\title{
Autocrine production of reproductive axis neuropeptides affects proliferation of canine osteosarcoma in vitro
}

\author{
Marcus A. Weinman', Jacob A. Fischer ${ }^{2}$, Dakota C. Jacobs², Cheri P. Goodall ${ }^{2}$, Shay Bracha ${ }^{1}$ and \\ Patrick E. Chappell ${ }^{2^{*}}$ (D)
}

\begin{abstract}
Background: Osteosarcoma strikes hundreds of people each year, of both advanced and younger ages, and is often terminal. Like many tumor types, these bone tumors will frequently undergo a neuroendocrine transition, utilizing autocrine and/or paracrine hormones as growth factors and/or promoters of angiogenesis to facilitate progression and metastasis. While many of these factors and their actions on tumor growth are characterized, some tumor-derived neuropeptides remain unexplored.

Methods: Using validated canine osteosarcoma cell lines in vitro, as well as cells derived from spontaneous tumors in dogs, we explored the autocrine production of two neuropeptides typically found in the hypothalamus, and most closely associated with reproduction: gonadotropin-releasing hormone (GnRH) and kisspeptin (Kiss-1). We evaluated gene expression and protein secretion of these hormones using quantitative RT-PCR and a sensitive radioimmunoassay, and explored changes in cell proliferation determined by MTS cell viability assays.

Results: Our current studies reveal that several canine osteosarcoma cell lines (COS, POS, HMPOS, D17, C4) synthesize and secrete $\mathrm{GnRH}$ and express the GnRH receptor, while COS and POS also express kiss 1 and its cognate receptor. We have further found that $\mathrm{GnRH}$ and kisspeptin, exogenously applied to these tumor cells, exert significant effects on both gene expression and proliferation. Of particular interest, kisspeptin exposure stimulated GnRH secretion from COS, similarly to the functional relationship observed within the neuroendocrine reproductive axis. Additionally, GnRH and kisspeptin treatment both increased COS proliferation, which additionally manifested in increased expression of the bone remodeling ligand rankl within these cells. These effects were blocked by treatment with a specific GnRH receptor inhibitor. Both neuropeptides were found to increase expression of the specific serotonin (5HT) receptor htr2a, the activation of which has previously been associated with cellular proliferation, suggesting that production of these factors by osteosarcoma cells may act to sensitize tumors to circulating $5 \mathrm{HT}$ of local and/or enteric origin.

Conclusions: Here we report that kisspeptin and GnRH act as autocrine growth factors in canine osteosarcoma cells in vitro, modulating RANKL and serotonin receptor expression in a manner consistent with pro-proliferative effects. Pharmacological targeting of these hormones may represent new avenues of osteosarcoma treatment.
\end{abstract}

Keywords: Osteosarcoma, GnRH, Kisspeptin, Autocrine, Proliferation

\footnotetext{
* Correspondence: patrick.chappell@oregonstate.edu

2Department of Biomedical Sciences, Carlson College of Veterinary Medicine,

Oregon State University, Corvallis, OR 97331, USA

Full list of author information is available at the end of the article
}

(c) The Author(s). 2019 Open Access This article is distributed under the terms of the Creative Commons Attribution 4.0 International License (http://creativecommons.org/licenses/by/4.0/), which permits unrestricted use, distribution, and reproduction in any medium, provided you give appropriate credit to the original author(s) and the source, provide a link to the Creative Commons license, and indicate if changes were made. The Creative Commons Public Domain Dedication waiver (http://creativecommons.org/publicdomain/zero/1.0/) applies to the data made available in this article, unless otherwise stated. 


\section{Background}

Osteosarcoma is the most common skeletal tumor in humans, striking a significant portion of people in their mid-20s, with a very low survival rate even with chemotherapeutic intervention $[1,2]$. Incidences of canine osteosarcoma are even higher, and the disease shares many characteristics with the human equivalent [3]. Amputation and adjuvant chemotherapy are the standard of care in dogs; however poor outcomes often result due to pulmonary metastasis [4]. To better address this disease in both species and potentially design novel targeted therapies, an enhanced understanding of local and systemic factors contributing to disease progression is essential. Recent evidence suggests an important role for serotonin (5HT) in normal bone physiology, and possibly an alteration of the role of $5 \mathrm{HT}$ in progression of osteosarcoma. Osteoblasts, osteocytes and osteoclasts express functional 5HT receptors (5HTR), and several remodeling pathways exhibit a dependency on circulating 5HT [5-7]. In investigating the role of $5 \mathrm{HT}$ in bone cancer, our group previously demonstrated a role for 5HTR in canine osteosarcoma in vitro using validated canine osteosarcoma cell lines (COS) [8]. In these studies, COS cells exhibited dose-dependent increases in proliferation following $5 \mathrm{HT}$ treatment. It was further demonstrated that expression of the 2A isoform of 5HTR (5HTR2A) was substantially increased in malignant cells in comparison to normal canine osteoblasts, ostensibly increasing the sensitivity of tumor cells to circulating $5 \mathrm{HT}$ [8].

The majority of circulating $5 \mathrm{HT}$ originates in enterochromaffin cells, and while this might play a role in regulating tumor growth rate, local autocrine and paracrine factors within tumor cells and surrounding stroma also likely modulate tumor progression, both by decreasing dependency on circulating factors or by sensitizing tumor cells to these factors. We posited that, similarly to what has been observed in other progressing tumor subtypes [9-11], osteosarcoma tumors may develop a neuroendocrine phenotype, synthesizing peptides often found in the hypothalamus. Gonadotropin-releasing hormone $(\mathrm{GnRH})$ synthesis and secretion has been documented mostly in reproductive cancers such as endometrial, ovarian, breast and prostatic cancers [1214]. GnRH receptor (GnRHR) expression was also demonstrated in the aforementioned reproductive cancers, with highly variable signaling effects on cancer proliferation [12]. Under normophysiologic conditions within the reproductive axis, continuous GnRHR stimulation results in receptor desensitization and downregulation of expression, while pulsatile GnRH secretion has little effect on GnRHR sensitivity and gnrhr transcript levels [12]. In cancers, the expression of GnRH has been associated with poor prognosis, but expression and production of this neuropeptide and its receptor in osteosarcoma remains unexplored. Additionally, the neuropeptide kisspeptin, indispensable for pubertal progression and fertility, may be synthesized in tumor cells (or neighboring stromal cells) and modulate tumor cell function of osteosarcoma [15-17]. This factor was formerly known as metastin, and was originally characterized in multiple tumor subtypes. While it is clear that kisspeptin plays an important role in initiating secretion of GnRH in the brain, the role of kisspeptin and its cognate receptor Kiss1R (a.k.a. GPR54) and their role in malignancy in cancer is still under investigation.

The bone remodeling system is governed by the protein triad of RANK (Receptor activator of Nuclear Factor K-B), RANKL (RANK-Ligand), and OPG (Osteoprotegerin). In normal remodeling, RANKL binds its cognate receptor, RANK, to stimulate osteoclastic maturation, activity, and subsequent bone resorption. Osteoblasts transiently synthesize RANKL and OPG, depending on their state of differentiation and exposure to afferent stimuli, while osteoclast precursors express RANK [18]. The OPG protein, also synthesized by osteocytes, functions as a decoy receptor for RANKL, such that the ratio of RANKL to OPG effectively dictates the amount of osteoclast formation and activity at any given time [19]. This homeostasis can be modulated by multiple circulating hormones. Estrogen, an ovarian steroid hormone, exerts a particularly profound effect on bone remodeling. Previous studies have shown that treatment of human osteoblasts with physiologic concentrations of estradiol increased estrogen receptor and OPG expression, which downregulates osteoclastic activity by preventing RANK-RANKL binding [20]. This response to estrogen creates a regulatory mechanism through which osteoblasts can modulate homeostasis of bone deposition and resorption dependent upon cycling steroid levels. This system becomes dysfunctional in tumor cells, both primary and secondary. In support of this, Good et al. performed a prospective study of cancer patients with primary and metastatic bone tumors that showed, via immunohistochemistry, that both types expressed RANKL [21]. Increases of the RANKL to OPG ratio by tumor cells, regardless of cellular origin, shifts the balance towards bone resorption and possible osteolysis.

Furthermore, RANKL-RANK binding activates the potent transcription factor NF- $\mathrm{B}$, which induces expression of an array of anti-apoptotic genes, promotes cell cycle progression, increases invasiveness, promotes angiogenesis, and induces inflammation [22]. Increases of the RANKL/OPG ratio therefore result in elevated NF- $\kappa B$ activation. While effects of estrogen have been explored, possible relationships between peptidergic reproductive hormones $\mathrm{GnRH}$ and kisspeptin and the RANK-RANKL-OPG system are unclear, since under 
normophysiologic conditions, GnRH is not found in the circulation. In a model of breast cancer, $\mathrm{GnRH}$ was shown to decrease in vitro rankl expression in $\mathrm{RANKL}^{+}$breast cancer cells co-cultured with human osteoblasts [23]. Regarding known interactions between $\mathrm{GnRH} /$ kisspeptin and NF-kB, Zhang et al. previously showed that NF- $\mathrm{kB}$ activation represses gnrh expression within the murine hypothalamus [24]. In the context of osteosarcoma, however, it is currently unknown whether $\mathrm{GnRH}$ or kisspeptin alter the function of the RANK-RANKL-OPG system, change NF- $\mathrm{KB}$ activation, or experience regulation of expression and secretion via NF- $\mathrm{kB}$.

In the current study, we sought to examine 1) if these typically reproductive neuropeptides (kisspeptin and $\mathrm{GnRH}$ ) are synthesized in canine osteosarcoma cell lines, 2) if GnRH may be secreted by these tumor cells, and 3) what effects autocrine production of these peptides could have on tumor growth and bone remodeling physiology. Additionally, we explored if the stimulatory effects of kisspeptin on GnRH synthesis and secretion found normally in the neuroendocrine reproductive axis are recapitulated in the local tumor microenvironment, including whether this relationship could be modulated by estrogen. Lastly, we investigated if these neuropeptides could modulate the previously characterized effects of $5 \mathrm{HT}$ on osteosarcoma growth rate.

\section{Methods}

\section{Validation of cell lines}

COS, HMPOS, POS, D17, C4 are well-characterized immortal canine osteosarcoma cell lines. COS were provided to SB by Dr. Vilma Yuzbazian (Michigan State Univ.). HMPOS (RRID:CVCL_L355), POS (RRID:CV CL_L413), D17 (RRID:CVCL_1916), and SAOS (RRID:CVCL_0548) cells were provided by ATCC. C4 (clone 4) canine osteosarcoma line was derived by Dr. Bernard Seguin at UC Davis, and provided to the Oregon State University Carlson College of Veterinary Medicine in 2014. Canine osteogenic progenitor cells (OPCs), which are committed (but not differentiated) mesenchymal stem cells, were purchased from Cell Application Inc., San Diego, CA. GT1-7 mouse hypothalamic neuronal line was provided by Dr. Pamela Mellon (UCSD). Validation markers for COS, POS, and HMPOS include western blot confirmation of bone-specific alkaline phosphatase, as well as osteoblast-specific markers run $x 2$ and $s p 7$, confirmed by RT-PCR. COS, POS, HMPOS, and SAOS cells were mycoplasma tested and confirmed clean as of April 2017.

\section{Cell culture and treatment}

Osteosarcoma tumor cells were grown in RPMI-1640 media supplemented with $10 \%$ fetal bovine serum (FBS), L-glutamine, sodium pyruvate, HEPES buffer, $100 \mu \mathrm{g} / \mathrm{mL}$
Streptomycin, 100 units $/ \mathrm{mL}$ Penicillin, and $50 \mu \mathrm{g} / \mathrm{mL}$ Gentamicin. Osteogenic progenitor cells (OPCs) were grown in a proprietary media supplied by the manufacturer (Cell Application Inc., San Diego, CA). GT1-7 cells (immortalized mouse GnRH neurons) were grown in DMEM with $10 \%$ FBS and $100 \mu \mathrm{g} / \mathrm{mL}$ Streptomycin and 100 units $/ \mathrm{mL}$ Penicillin. All cells were incubated in $37^{\circ} \mathrm{C}$ at $5 \% \quad \mathrm{CO}_{2}$ and grown to confluence for experiments.

\section{PCR and sequencing}

Genomic DNA and total RNA were extracted from plates of confluent cells using the QIA DNA Mini-Kit (Qiagen) and TriZol, respectively. Specific primers were designed to amplify within the coding regions of $\beta$-actin, gpr54, gnrh, htr2a, kiss1, gnrhr, rank, rankl, opg, and ywhaz. PCR products were validated via gel electrophoresis (2\% agarose) with ethidium bromide. Sequencing was performed by the Center for Genome Research and Biocomputing at Oregon State University; sequences were confirmed against the published sequences at the National Center of Biotechnology Information website.

\section{Real-time RT-PCR}

One microgram total RNA extracted from OPC, GT1-7, COS, HMPOS and POS, via standard methods, was converted to cDNA using High Capacity cDNA Reverse Transcription Kit (Life Technologies, Eugene, OR). Real-time PCR compatible primer pairs were designed for canine $\beta$-actin, kiss1, gpr54, gnrh, gnrhr, htr2a, rank, rankl, opg, and ywhaz, (Additional file 2: Table S1) using the NCBI's Primer-BLAST (http://www.ncbi.nlm.nih.gov/tools/primer-blast/). PCR was executed with Power SYBR Green (Life Technologies, Eugene, OR) using a StepOnePlus real-time thermal cycler (ABI/ThermoFisher). Relative gene expression was calculated by the $2^{-\Delta \Delta \mathrm{CT}}$ method in relation to the endogenous expression of $y$ whaz and/or $\beta$-actin at each time point. Values shown are normalized to vehicle $(0.1-0.01 \%$ DMSO) control.

\section{Cell viability assay}

Viability assays were performed with CellTiter $96^{\circ}$ Aqueous One Solution (Promega, Madison, WI), which is a MTS tetrazolium assay. Cells were plated in triplicate on 96-well culture plates at $1 \times 10^{4}$ cells per well and incubated in serum free media for $24 \mathrm{~h}$, after which time the media was replaced by a fresh light-treated media that contained 0.1\% DMSO for the control untreated groups or $6.0 \mu \mathrm{M} 5 \mathrm{HT}$, following $24 \mathrm{~h}$ of $1.0 \mathrm{nM} \mathrm{GnRH}$ pre-treatment. Treatments not involving $5 \mathrm{HT}$ were carried out with as described with DMSO for the untreated control groups or $1.0 \mathrm{nM}$ GnRH, $10.0 \mathrm{nM}$ Kisspeptin, $10.0 \mathrm{nM}$ Teverelix, $100.0 \mathrm{pM} 17 \beta$-estradiol, or listed 
combinations of the above for treatment groups. Cells were processed following manufacturer's instructions and absorbance was measured at $490 \mathrm{~nm}$ on a microplate reader.

\section{Statistical analyses}

Cell viability data from the proliferation assay were analyzed using a generalized linear model to account for variation due to time and concentration of $5 \mathrm{HT}$ and GnRH. The resulting model was then subjected to one-way ANOVA analysis, followed by Tukey's Honest Significant Difference test to compare the effects of dose increases separately or in combination at differing times. ANOVA and Tukey's HSD analyses were carried out using GraphPad Prism software. Statistical significance was assigned for calculated values of $p<0.05$.

\section{Cell perifusion}

COS were transferred to adherent Cytodex 3 beads and incubated in petri dishes for 24-96 h. Cells on beads were loaded into $1.0 \mathrm{cc}$ columns in a $37.0^{\circ} \mathrm{C}$ incubator and perifused with serum-free RPMI at a flow rate of $100 \mu \mathrm{L} / \mathrm{min}$ using a Gilson peristaltic pump. One milliliter fractions were collected every 10 min using refrigerated Gilson fraction collectors. Perifusates were frozen at $-20^{\circ} \mathrm{C}$ until $\mathrm{GnRH}$ radioimmunoassay. Media containing either $10.0 \mathrm{nM}$ kisspeptin-10, $6.0 \mu \mathrm{M}$ serotonin, or $12.5 \mu \mathrm{M}$ ritanserin was perifused over COS cells for two hour intervals, followed by washout for $2-4 \mathrm{~h}$.

\section{Radioimmunoassay}

Media from cells collected in static incubation were concentrated 1:5 and resuspended in $100 \mu \mathrm{L}$ PBS-G/replicate. One hundred microliters media from perifusate were assayed directly using the EL-14 primary antibody (gift from M. Kelly and O. Ronnekleiv). Intra- and interassay $\mathrm{CV}$ was 4.9 and $6.7 \%$, respectively.

\section{Immunoblotting}

Total protein concentrations from COS, OPC, and GT1-7 cell lysates were determined via BCA assay kit (Pierce Biotechnologies, Rockford, IL). Plates were read using a SkanIt plate-reader (Thermo Fisher Scientific, Waltham, MA) at absorbance of $562 \mathrm{~nm}$. Twenty-five micrograms of protein were separated on a $10 \%$ polyacrylamide gel and transferred to a nitrocellulose membrane. Primary antibodies for GPR54/ Kiss1R (Alamone, Jerusalem, Israel) were used to probe blots. Bound primary antibody was probed by goat anti-rabbit HRP and detected with Supersignal West Pico Chemiluminescent Substrate (Thermo Scientific, Waltham, MA). The blots were scanned on an ImageQuant LAS4000 (GE Healthcare Life Sciences, Marlborough, MS). Anti-alpha-tubulin followed by goat anti-rabbit HRP (Santa Cruz Biotechnology, Dallas, TX) were used to assess protein loading and normalize band intensities.

\section{Results}

Expression of reproductive neuropeptides and bone remodeling factors in canine osteosarcoma cell lines

To explore if canine osteosarcoma cells may employ reproductive neurohormones and their receptors as autocrine/paracrine factors, we probed established tumor cell lines for expression of canine gnrh and kiss1, and their respective cognate receptors gnrhr and gpr54/kiss1R, using RT-PCR (Fig. 1a-d). GnRH expression was observed in all lines examined, found also in primary canine tumors acquired from the Oregon State University College of Veterinary Medicine BioBank, and at lower levels in normal canine osteogenic progenitor cells (OPC) (Fig. 1a, e). Low basal levels of kiss1 expression were observed in COS and POS lines (Fig. 1b), but not in D17, HMPOS, or OPCs. Pituitary-typical gnrhr expression was also observed in canine osteosarcoma lines COS, C4, and D17, and primary tumor samples, in addition to OPC (Fig. 1c). Kiss1r (gpr54) expression was observed in all osteosarcoma cells tested, primary samples, and normal OPCs (Fig. 1d). Isolated amplicons from these samples were confirmed by Sanger sequencing, which showed near-complete sequence homology (data not shown). GnRH receptor was expressed at similar levels among cultured cell lines, suggesting a threshold presence of receptor to respond to exogenously-applied GnRH, which exerted multiple effects on gene expression and proliferation in COS, effects that were blocked by the GnRHR inhibitor, Teverelix (see below).

Noting potential quantitative differences in kiss1r between COS and OPC using RT-PCR, we quantified expression and compared levels between this tumor line and normal canine osteogenic progenitor cells. Real-time RT-PCR results reveal that expression of kiss $1 r$ is present at elevated levels ( $\sim$-fold higher) in COS compared to normal osteogenic progenitor cells (Fig. 1f), which accompanied by absent kiss 1 expression in the latter cells (Fig. 1b), suggests a potential aberration of the kisspeptin peptide/receptor system in this type of cancer (Fig. 1d, e). Immunoblotting confirmed the presence of translated Kiss1R in two canine osteosarcoma lines, COS and POS, while Kiss1R protein was not detected in osteogenic progenitor cells (Fig. 1g). RT-PCR was also used to determine rank and rankl expression in COS cells and OPCs. COS cells express both rank and rankl, while osteogenic progenitor cells were found to express rank but not rankl (Fig. 1h, i), potentially because rankl expression is typically induced by stromal signals that promote osteoblastic differentiation of osteogenic progenitor cells. Additionally, rank expression in normal osteoblasts has been observed previously [25], and this pattern of rank/ rankl expression in our OPCs may reflect a particular state of incomplete differentiation. 


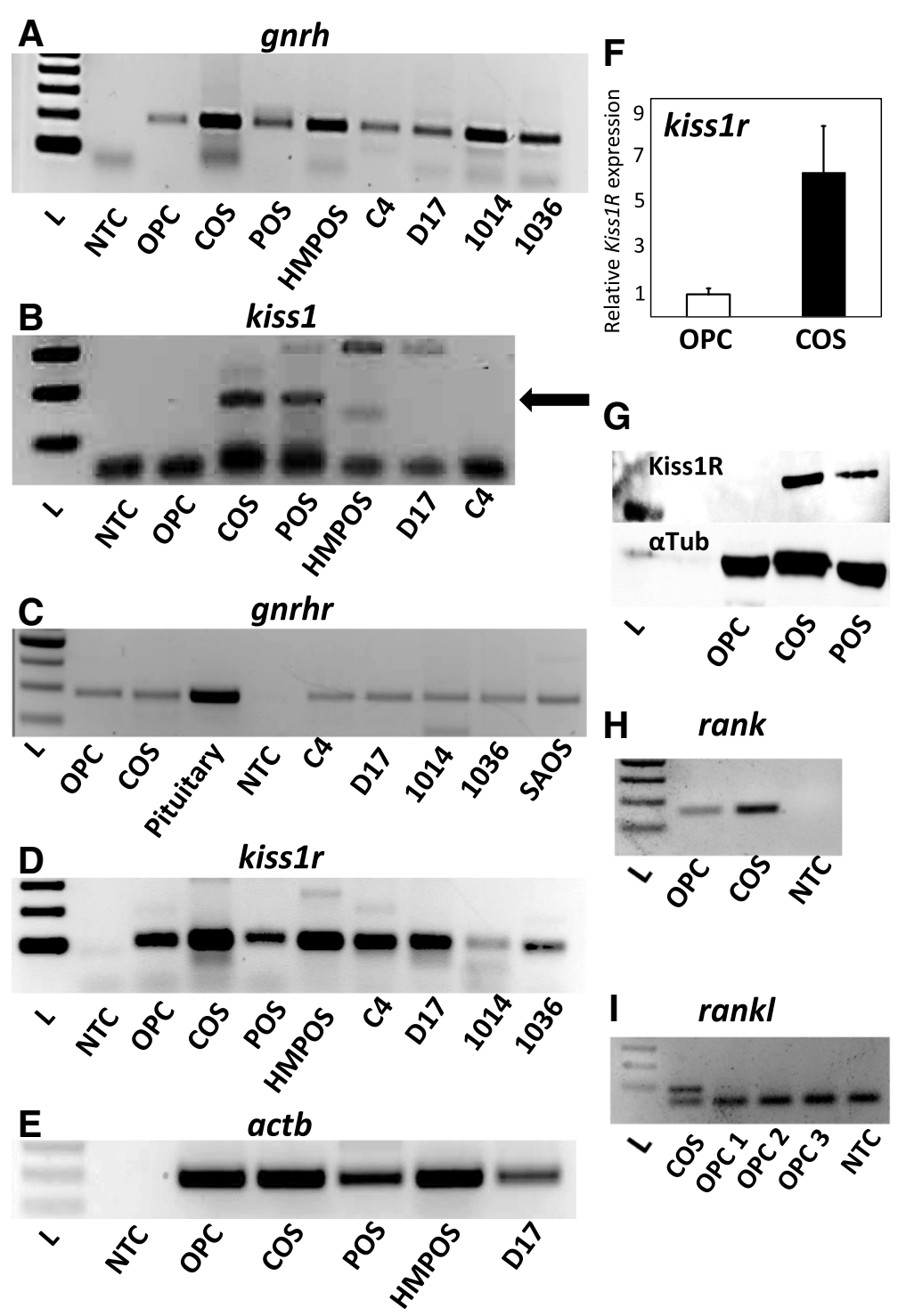

Fig. 1 (a) gnrh (b) kiss1, (c) gnrhr, and (d) gpr54/kiss1r mRNA expression in normal canine osteoblasts (OPC), multiple osteosarcoma cell lines (COS, POS, HMPOS, C4, D17, human SAOS) and clinical patient-derived samples $(1014,1036)$. Arrow in (b) indicates kiss 1 band. PCR primers used can be found in Additional file 2 Table S1. e $\beta$-actin (actb) expression in OPC, COS, POS, HMPOS, and D17 cells. f Relative levels of cKiss $1 R$ expression in COS vs. OPC. $\mathbf{g}$ Immunoblot of Kiss1R protein (54kD, upper band) in normal canine osteoblasts (OPC) and osteosarcoma lines (COS, POS); a-tubulin (42kD, lower band) was also probed as a control. $\mathbf{h}$ RT-PCR expression of rank in COS vs. OPC. i RT-PCR expression of rankl in COS vs. OPC (3 preparations). NTC indicates RNA (no cDNA template) control

Using primer sets listed in Additional file 2: Table S1, we were able to sequence the complete coding region of canine kiss 1 . The sequence is $100 \%$ homologous to that which had been recently submitted to GenBank (accession number KJ512885) by Reynaud, et al. Nucleotide and amino acid sequence comparison of kiss 1 and kisspeptin are found in Additional file 1: Figure S1, demonstrating that canine kisspeptin is unique. A previous study [26] also found that the predicted protein and mRNA sequence for kisspeptin in the dog was substantially different from kisspeptin in other species. Using real-time $\mathrm{qPCR}$, we noted kiss1 expression in a two osteosarcoma cell lines (COS and POS), but not in normal osteogenic progenitor cells (OPC).

\section{GnRH is secreted from COS, and this secretion is} stimulated by kisspeptin

To determine if the mature GnRH decapeptide may also be synthesized and secreted by COS to potentially act as an autocrine factor, we measured GnRH secretion from these tumor cells in multiple culture formats using a sensitive radioimmunoassay [27]. Briefly, COS were 
grown both in static incubation in tissue culture flasks, as well as on adherent Cytodex 3 beads for subsequent cell perifusion and fraction collection [27]. As observed in Fig. 2, COS secrete low $(\sim 2-5 \mathrm{pg} / \mathrm{ml})$ but detectible concentrations of $\mathrm{GnRH}$ into the media under basal conditions. Strikingly, this secretion from COS is stimulated 4-5 fold by $10.0 \mathrm{nM}$ human kisspeptin-10 treatment $(18.2 \pm 2.8 \mathrm{pg} / \mathrm{ml})$, both in the presence and absence of $100.0 \mathrm{pM} 17 \beta$-estradiol $\left(22.5 \pm 0.8 \mathrm{pg} / \mathrm{ml} ;{ }^{*}, p\right.$ $<0.05 ; n=6$, Fig. 2a). Secretion of $\mathrm{GnRH}$ was also noted from COS grown in cell perifusion format, appearing pulsatile, with similar secretory parameters observed in immortalized GnRH-secreting GT1-7 [27, 28]. In this

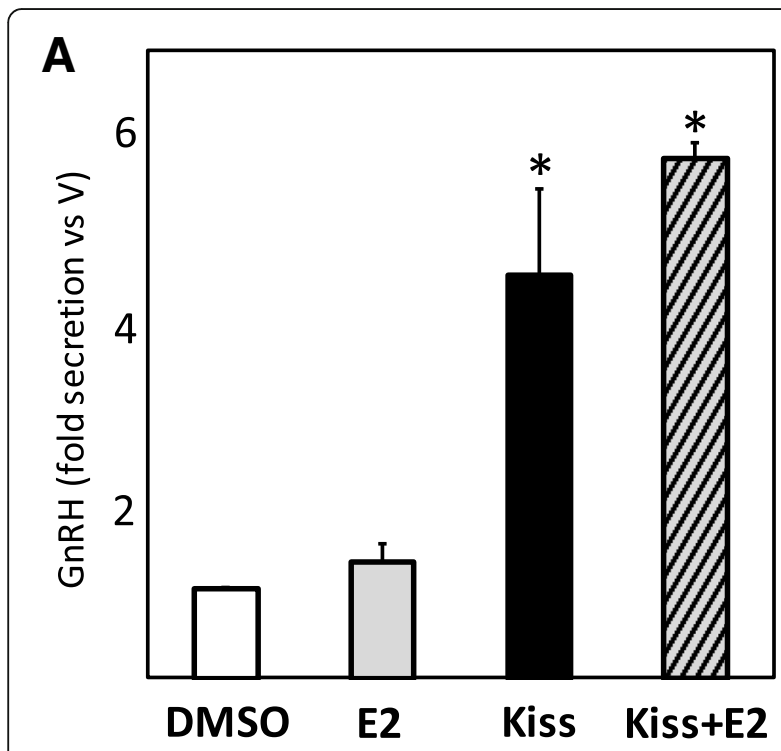

B

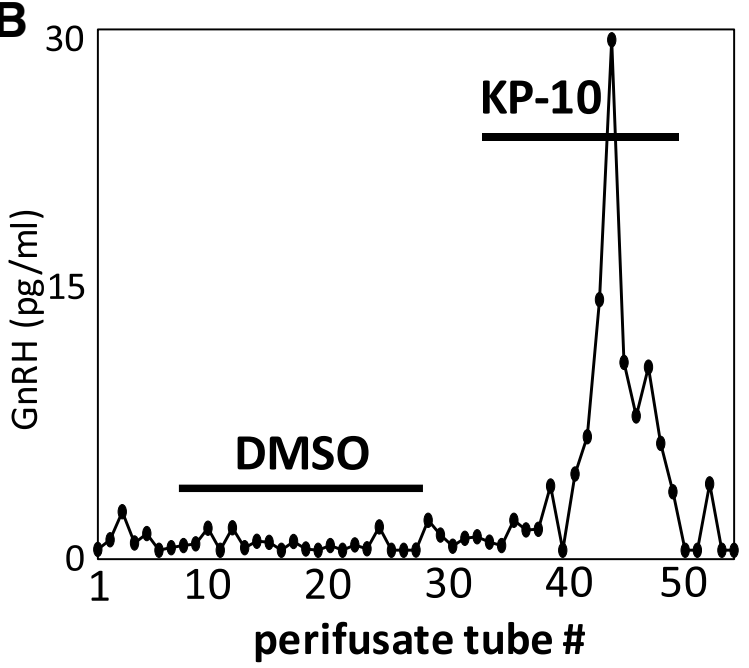

Fig. 2 a $\mathrm{GnRH}$ secretion in static incubation from media of COS in vitro treated for $4 \mathrm{~h}$ with $17 \beta$-estradiol (100.0 pM), kisspeptin-10 (10.0 nM), or a combination of E2 and kisspeptin-10. b Representative plot of GnRH secretion from perifused COS treated with either $0.05 \%$ DMSO vehicle or 10.0 nM kisspeptin-10. Lines indicate duration of exposure to drug/vehicle format as well, $10.0 \mathrm{nM}$ kisspeptin-10 was found to rapidly and transiently stimulate GnRH secretion from perifused COS in comparison to DMSO vehicle treatment (KP-10: $28.5 \pm 1.9 \mathrm{pg} / \mathrm{ml}$ vs. DMSO: $3.7 \pm 0.4 \mathrm{pg} / \mathrm{ml} ;{ }^{*}, P$ $<0.05, n=6$ ), which had no observable effect on GnRH secretory baseline (representative perifusion, Fig. 2b).

\section{Treatment of COS with exogenous GnRH and kisspeptin alters cellular viability}

To investigate if exposure to GnRH or kisspeptin could modulate tumor growth in vitro, we performed cell viability assays following treatment of COS with these peptides. MTS assays revealed a dose-dependent effect of $\mathrm{GnRH}$ on COS proliferation, with lower doses of $\mathrm{GnRH}$ (0.1-1.0 $\mathrm{nM})$ exerting significant $(\sim 35 \%$ increase $\pm 6.4 \%$; $p<0.05 ; n=6)$ increases in COS proliferation above vehicle treatment (Fig. 3a). We previously demonstrated that exogenously applied serotonin (5HT) could alter proliferation of COS in vitro [8]. To determine if GnRH and/or kisspeptin may potentiate or counter these effects of $5 \mathrm{HT}$ on tumor growth, COS were treated with doses $(0.5,3,6,12$, and $25 \mu \mathrm{M})$ of this indoleamine for $24 \mathrm{~h}$ following treatment with either $1.0 \mathrm{nM} \mathrm{GnRH}$ or 10.0 $\mathrm{nM}$ kisspeptin, and proliferation was again evaluated via MTS assay. Sequential co-incubation of COS with 5HT and $10.0 \mathrm{nM}$ GnRH resulted in potentiation of COS proliferation above 5HT treatment alone, particularly at doses of $6-25 \mu \mathrm{M}$ 5HT (*, $p<0.05 ; * *, p<0.01 ; \mathrm{n}=6 /$ treatment; Fig. 3 a, b). Interestingly, KP-10 co-treatment with $5 \mathrm{HT}$ exerted no additional effects on cell growth above that observed for $5 \mathrm{HT}$ treatment alone (data not shown). To further examine how these neuropeptides may alter tumor growth, additional MTS assays were performed with GnRH, kisspeptin, and the GnRH receptor inhibitor Teverelix, both individually and in combination. These treatments illustrate that kisspeptin and $\mathrm{GnRH}$ both increase COS proliferation above control, while antagonism of GnRHR via co-incubation with Teverelix (10.0 nM) attenuated both GnRH- and Kisspeptin-stimulated increases in proliferation (Fig. 3c, *\%, $\mathrm{p}<0.01 ; * *, p<0.001 ; n=5$ /treatment), suggesting that kisspeptin may increase COS cell proliferation via GnRH-dependent mechanisms.

\section{Hormone treatment modifies the bone remodeling} system through potentiation of rankl expression To further investigate mechanisms of how 5HT, GnRH, kisspeptin, and estrogen treatment may alter growth of COS cells, we performed cell culture treatments with these hormones and quantified changes in gene expression for rank, rankl, and opg at 4-h post-treatment. Both $\mathrm{GnRH}$ and kisspeptin increase rankl gene expression (Fig. 4b, *, $p<0.05, n=6 /$ treatment). The presence of Teverelix in combination with $\mathrm{GnRH}$ reduced rankl 


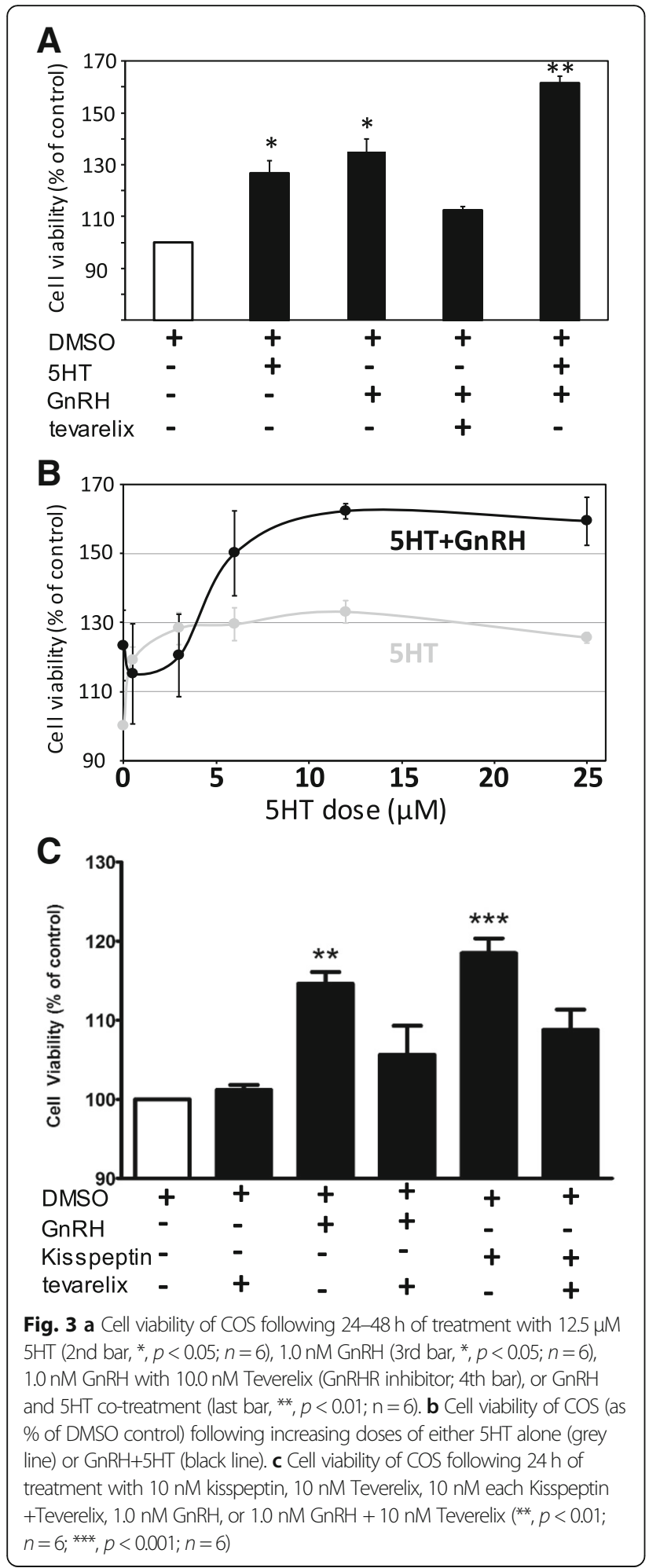

expression by $50 \%$ in comparison to $\mathrm{GnRH}$ alone. These results suggest that $\mathrm{GnRH}$ and kisspeptin favor an increase in the RANKL/OPG ratio, which would increase downstream NF-kB activation. Gene expression for rank trends upwards $(p<0.057)$ towards a 2-fold increase

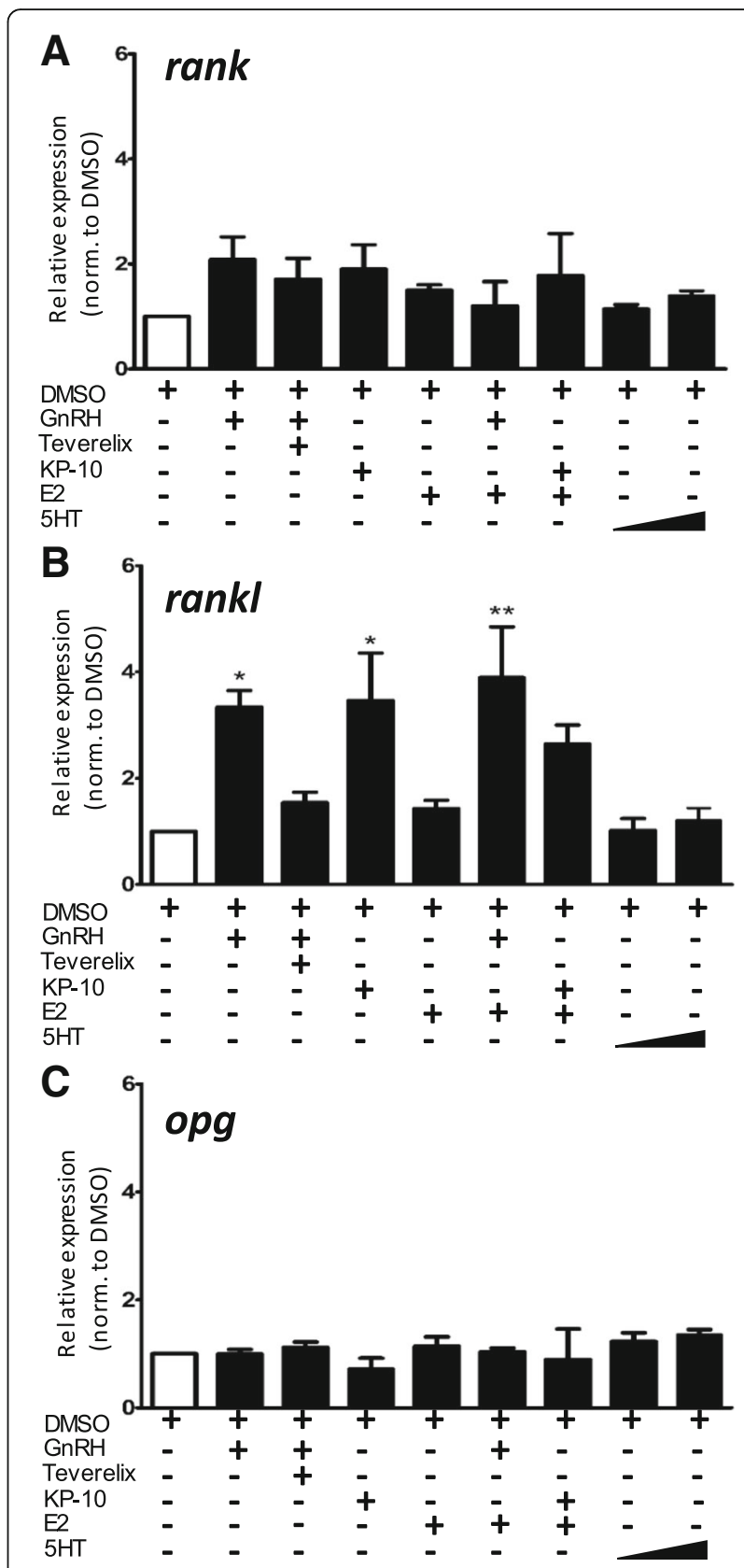

Fig. 4 a Changes in rank gene expression after treatment with 1.0 nM GnRH, 1.0 nM GnRH + 10.0 nM Teverelix, 10.0 nM kisspeptin, 100.0 pM 17ß-estradiol, 1.0 nM GnRH + 100 pM 17ß-estradiol, 10.0 nM kisspeptin + 100.0 pM 17 $\beta$-estradiol, or 5HT (3.0 $\mu \mathrm{M}$ and 12.0 $\mu \mathrm{M})$. $\mathbf{b}$ Changes in rankl gene expression after treatment with hormones described above ( ${ }^{*}, p<0.05 ;{ }^{* *}, p<0.01, n=6 /$ treatment). c Changes in opg gene expression after treatment with hormones described above

after treatment (Fig. 4a), suggesting that, over time, rank expression may continue to increase with $\mathrm{GnRH}$ and kisspeptin treatment. No significant changes in opg expression were observed (Fig. 4c). Not surprisingly, in these transformed tumor cells, estrogen fails to exert its 
normal physiologic effect of increasing opg expression to counteract increasing levels of RANKL protein. Serotonin treatment, at either low $(3.0 \mu \mathrm{M})$ or high $(12.0 \mu \mathrm{M})$ doses, had no effect on expression levels of any of the bone remodeling factors.

\section{GnRH and kisspeptin treatment increases expression of $5 \mathrm{HT}$ receptor htr2A}

We recently demonstrated that exogenous $5 \mathrm{HT}$ treatment of COS, putatively representative of enteric $5 \mathrm{HT}$ in vivo, could modulate expression levels of the serotonin receptors $h \operatorname{tr} 2 A$ and $h \operatorname{tr} 1 B$, leading to changes in proliferation via the constitutive phosphorylation of ERK and CREB [8]. To determine if exposure to these reproductive neuropeptides may potentiate the pro-proliferative effects of $5 \mathrm{HT}$, we evaluated the effects of exogenous GnRH and kisspeptin-10 treatment on levels of the specific $h t r 2 A$ isoform of $5 \mathrm{HT}$ receptor. Real-time RT-qPCR (Fig. 5) revealed that $1.0 \mathrm{nM} \mathrm{GnRH}$ and $10.0 \mathrm{nM}$ kisspeptin-10 increased $h$ tr $2 a$ expression 2- (at $24 \mathrm{~h}$ ) to 8-fold (at $4 \mathrm{~h}$ ) over levels observed in vehicle-treated COS (*, $p<0.05 ; n$ $=6$ ), suggesting these peptides may potentiate 5HT-stimulated growth at least in part by increasing abundance of the pro-proliferative receptor isoform HTR2A. Kisspeptin treatment also increased expression of htr1b, with significant increases (*, $\mathrm{p}<0.05 ; \mathrm{n}=6$ ) not observed until $24 \mathrm{~h}$ following exposure, in contrast to the transiently robust increases observed for $h t r 2 a$ expression.

Interestingly, exposure of perifused COS cells to $12.5 \mu \mathrm{M} 5 \mathrm{HT}$ also rapidly and transiently increased GnRH secretion (Fig. 6a), while treatment with the specific 5HTR2A inhibitor ritanserin blunted GnRH secretion, followed by a rebound in secretion during inhibitor washout (Fig. 6b). These results suggest that $5 \mathrm{HT}$ may also act on the release of $\mathrm{GnRH}$ as a positive feedback loop within osteosarcoma tumors.

\section{Discussion}

Canine and human osteosarcoma unfortunately often develops rapidly to terminal stages due to metastases to lungs and other sites [3]. Thus, elucidation of mechanisms used by these tumors to maintain proliferation rate and establish independence within their specific microenvironment could be helpful in establishing targeted therapies. In this study, we identified two peptides, GnRH and kisspeptin, typically found as key signals within the neuroendocrine reproductive axis, exerting effects on cultured canine osteosarcoma tumor cells in vitro, and further found that the normally-observed stimulatory regulation of kisspeptin on $\mathrm{GnRH}$ secretion is recapitulated within these cells. In addition to being expressed in established osteosarcoma lines, GnRH also appears to be expressed in primary tumor samples from canine patients. Secretion of $\mathrm{GnRH}$ from COS was

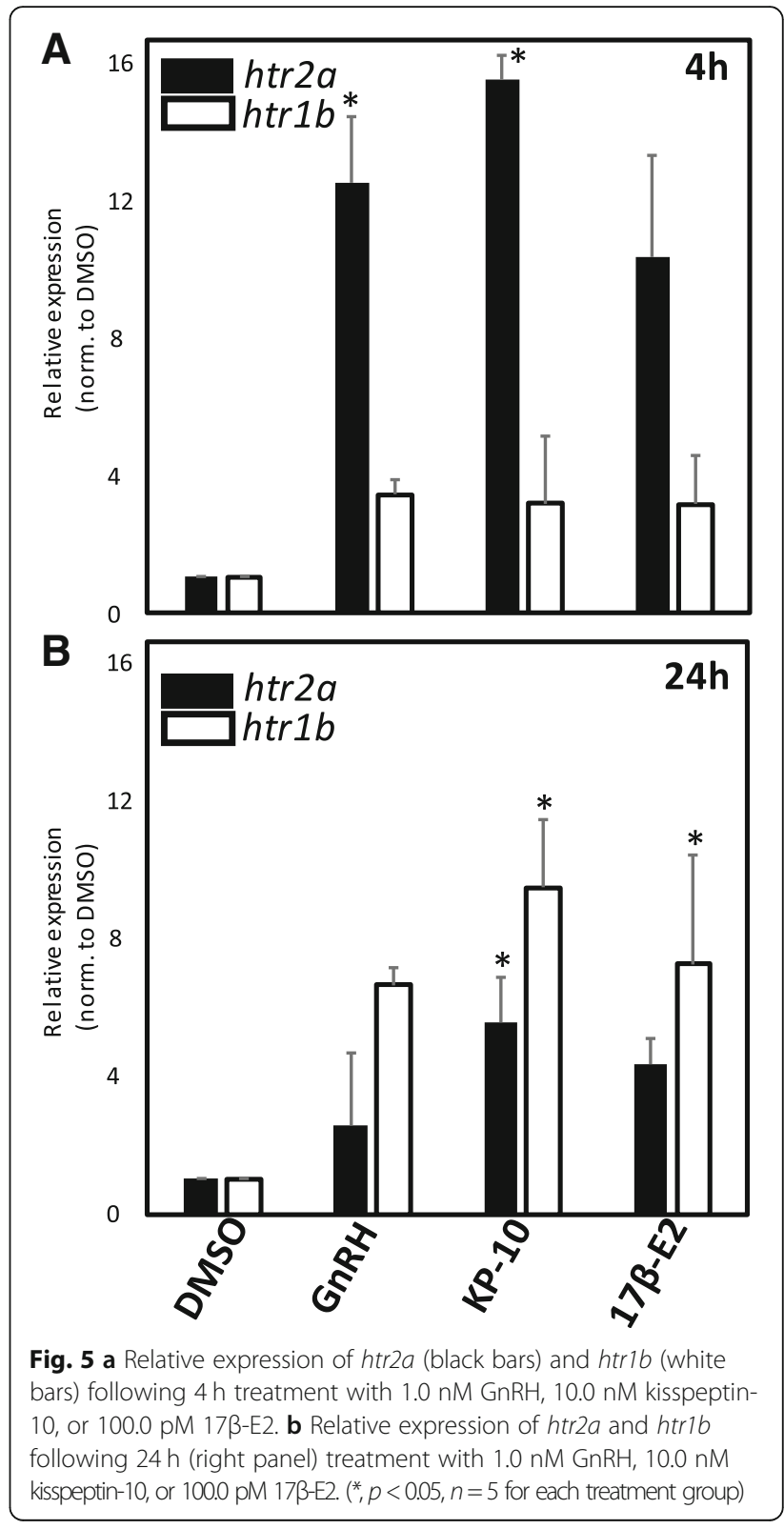

detected using radioimmunoassay, demonstrating that these cells can secrete this decapeptide in measurable amounts, and that this basal release of GnRH could be stimulated by exposure to human kisspeptin. While this current study also reveals that a few canine osteosarcoma cell lines synthesize kiss1, the possibility cannot be excluded that circulating levels of kisspeptin from the liver or other distal or proximal sites may typically act on cognate Kiss1R in these tumors. Kiss 1 expression has been previously noted in human osteosarcoma cell lines and adjacent tissues [16] as well as in other cancer cell types [29-31]. Canine kisspeptin appears to be markedly different from the human and murine version of the peptide [26], and while we were able to detect 

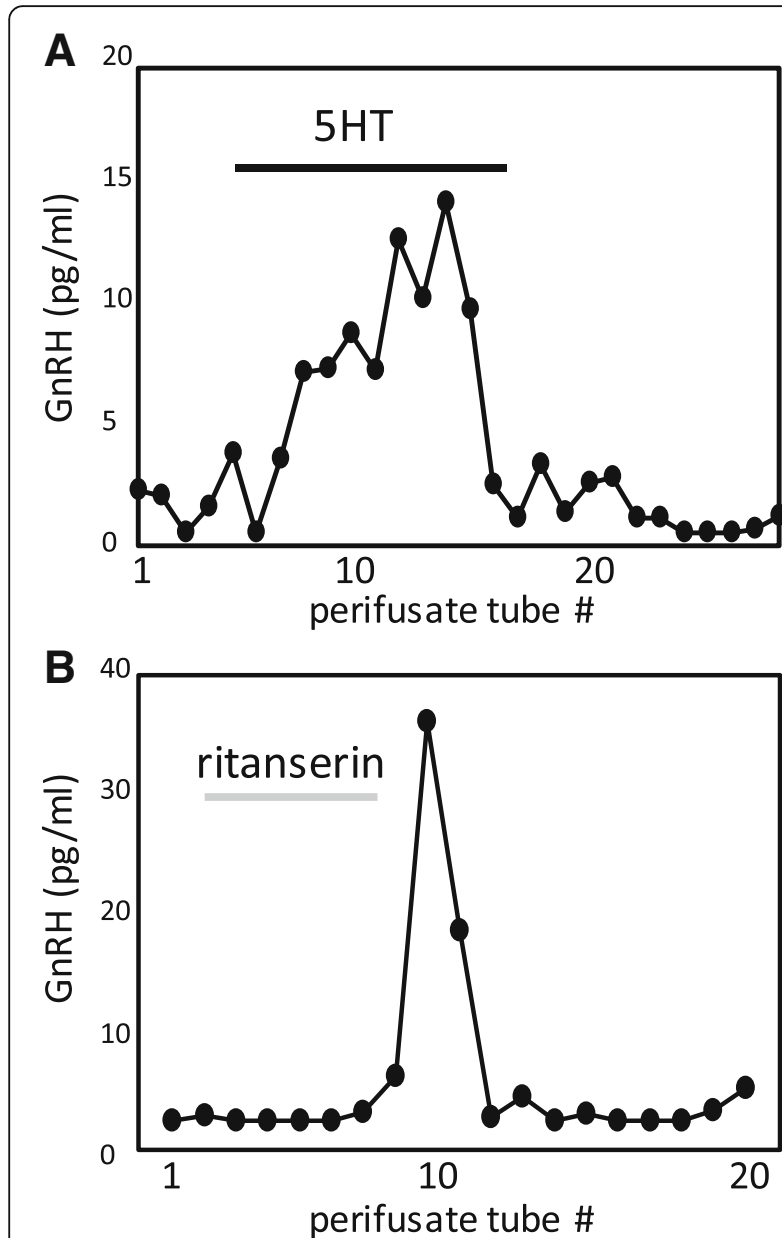

Fig. 6 a Representative plots of GnRH secretion from perifused COS treated with $12.5 \mu \mathrm{M} 5 \mathrm{HT}$ for duration indicated by black bar. $\mathbf{b} \mathrm{GnRH}$ secretion from perifused COS treated with $6.0 \mu \mathrm{M}$ 5HTR2A-specific inhibitor ritanserin for duration indicated by grey bar

expression in some tumor lines via RT-PCR, it is unclear if the peptide is synthesized, since a canine-specific ELISA is currently unavailable. As normal canine osteogenic progenitor cells appear to possess significantly lower levels of Kiss1R expression, it would seem that tumor cells may selectively up-regulate this receptor, and that Kiss1R signaling is less frequently observed in a normophysiologic context. The expression of kiss1r observed in normal canine osteogenic progenitor cells could be due to the transcription factor Runx2 activating kiss $1 r$, which is consistent with OPCs expressing runx2 as a function of osteoblastic lineage commitment [32]. Additionally, previous studies have observed variable expression levels of the kiss1r transcript in normal osteogenic progenitor cells and mesenchymal stem cells, resulting in varying amounts of Kiss1R protein synthesis, occasionally including no detectable protein [33]. In other cancer types, several studies demonstrate that kisspeptin may act as a tumor suppressor [34-36], while a handful of recent studies suggest that Kiss1R activation may promote breast tumor proliferation and metastasis [37-39].

Additionally, while we observed effects of $\mathrm{GnRH}$ in osteosarcoma cell lines in the form of changes in proliferation and gene expression, the pituitary-typical transcript of GnRHR was found to have a significantly low basal abundance in COS cells. This is consistent with the normophysiologic effect of downregulating gnrhr expression in response to continuous GnRHR stimulation by GnRH. Potential induction of gnrhr expression by kisspeptin and/or pulsatile GnRH treatment suggests that autocrine and paracrine signaling, mediated by endogenous production of these peptide hormones by tumor cells, is sufficient to maintain adequate transcript abundance for GnRHR protein production, which could subsequently sensitize COS cells to further $\mathrm{GnRH}$. In support of this, GnRH effects on proliferation are reversed by application of the GnRHR antagonist Teverelix suggesting that the receptor is not desensitized in the presence of constitutive $\mathrm{GnRH}$ production and non-pulsatile GnRH secretion.

While some studies of human osteosarcoma and breast cancer suggest that GnRH may decrease metastasis [12, 40], our data, in contrast, suggest a model by which autocrine production of $\mathrm{GnRH}$ may allow canine bone cancer an additional way to maintain and progress. One hallmark of cancer is sustaining proliferative signaling [41, 42], which can be provided by autocrine or paracrine signals that override normal apoptotic mechanisms, tilting the balance toward unregulated cell proliferation. We have previously shown that $5 \mathrm{HT}$ can act at HTR2A, which are strikingly upregulated in osteosarcoma cells, to influence growth rate [8]. Our current model posits that minor amounts of circulating $5 \mathrm{HT}$ can induce production and/or release of GnRH from tumor cells, which can be potentiated by either autocrine or circulating kisspeptin. Increases in GnRH exposure could then allow for tumor proliferation, partially by increasing $h t r 2 a$ expression, thus leading to a positive feedback growth response upon subsequent exposure to enteric 5HT. Circulating and/or autocrine kisspeptin could alter tumor proliferation rate by stimulating autocrine GnRH release. Gpr54/Kiss1R expression was observed in normal osteoblast cells at levels significantly lower than what was found in tumor lines. While not fully confirmed, this suggests that Kiss-1 signaling in cancer cells may act both as a growth factor (via increases in the autocrine production of $\mathrm{GnRH}$ ), and a tumor suppressor (independently of GnRH). Kisspeptin treatment in the presence of blockade of GnRH action by Teverelix resulted in a decrease in proliferation compared to that observed with kisspeptin alone, further suggesting that Kiss-1 may increase proliferation in a GnRH-dependent manner.

COS cells are primarily osteoblastic, yet express both rank and rankl (in addition to opg), potentially 
conferring the ability to signal in autocrine and paracrine manners to modulate proliferative rate. Thus, factors that may potentially modulate rank, rankl, and opg expression - such as GnRH, kisspeptin, 5HT, and estrogen - may further influence tumor progression, due to the anti-apoptotic and pro-proliferative effects of NF- $\mathrm{kB}$ activation. Our data indicate that $\mathrm{GnRH}$ exposure increases rankl expression, which may account for its observed effect to increase proliferation. This effect appears to be receptor-specific, as it was also negated by Teverelix, which suggests an unknown mechanism of rankl potentiation exists downstream of GnRHR activation. Despite the eventual activation of $\mathrm{NF}-\mathrm{\kappa B}$ via RANKL, the expected downregulation of gnrh expression by NF- $\mathrm{kB}$ may be negated due to the presence of autocrine, paracrine, and circulating 5HT and/or kisspeptin, which would continue to promote gnrh expression. Interestingly, estrogen treatment elicited no additional changes in opg expression under any peptide hormone treatment, denoting a significant loss of normal osteoblastic behavior. COS cells are known to express $E R \alpha$, which indicates they should be able to respond to circulating estrogen and subsequently increase opg expression. Failure to do so after estrogen treatment denotes a second aspect of dysregulation in bone remodeling. By increasing the RANKL/OPG ratio, irrespective of the presence of estrogen, $\mathrm{GnRH}$ and kisspeptin may thus disrupt bone remodeling homeostasis to favor osteoclastic activity, which may further accelerate the growth and spread of osteosarcoma.

Due to limitations inherent in in vitro model studies, further exploration is required to more completely determine what effects locally-produced kisspeptin and $\mathrm{GnRH}$ are exerting within the tumor microenvironment, including investigating changes in downstream signaling, and what similarities and differences exist between our findings and what may be found in an in vivo context. While many mechanistic details remain to be addressed, our current studies raise the possibility of targeting this traditionally-associated neuroendocrine signaling pathway, as well as RANKL protein, in a therapeutic manner for the treatment of osteosarcoma in dogs and potentially humans as well.

\section{Conclusions}

In this study, we found that canine osteosarcoma cell lines and primary tumor samples express neuroendocrine hormones and receptors typically associated with the reproductive axis, such as gnrh, kiss1, gnrhr, and kiss1r, at differential levels in comparison to normal osteogenic progenitor cells. These expression patterns were associated with a functional sensitivity to autocrine, paracrine, and/ or circulating $\mathrm{GnRH}$ and kisspeptin, as revealed by kisspeptin-induced GnRH secretion from COS cells.
Further, proliferation of osteosarcoma cells was significantly altered by reproductive hormone exposure, as treatment of COS cells with exogenous kisspeptin, $\mathrm{GnRH}$, and $5 \mathrm{HT}$ exerted pro-proliferative effects, which may be potentiated by increases in rankl and 5htr $2 a$ expression. Lastly, exogenous $5 \mathrm{HT}$ was also found to increase $\mathrm{GnRH}$ secretion, establishing an additional positive feedback loop that may drive constitutive growth and signaling. Pro-proliferative effects were reversed by treatment with GnRHR and 5HTR2A antagonists, suggesting that these neuroendocrine hormones should be included in a list of viable targets for the treatment of osteosarcoma.

\section{Additional files}

Additional file 1: Figure S1. Comparison of nucleotide sequences of kiss1 (A) and amino acid sequences of Kiss-1 (B) in the dog, human, and mouse. (PDF $462 \mathrm{~kb}$ )

Additional file 2: Table S1. Nucleotide sequences of specific PCR primers. (PDF 336 kb)

\section{Abbreviations}

COS: HMPOS, POS, D17, C4, canine osteosarcoma cell lines:

$\mathrm{GnRH}$ : gonadotropin-releasing hormone; kiss 1: kisspeptin gene; opg: Osteoprotegerin; rank: Receptor Activator of Nuclear Factor k-B; rankl: RANK-Ligand

\section{Acknowledgements}

The authors would like to thank the Departments of Biomedical and Clinical Sciences at the Oregon State University College of Veterinary Medicine for continuing support for supplies and reagents.

\section{Author contribution}

S.B. and P.C. were responsible for experimental design; M.W. and J.F. performed PCR/qPCR, immunoblotting, and cell viability assays; D.J. performed cell perifusion and APCR; C.G. sequenced and aligned the canine kiss 1 transcript; M.W. and P.C. performed statistical analysis; M.W., S.B. and P.C. were responsible for manuscript writing and editing.

\section{Funding}

This research did not receive any specific grant from any funding agency in the public, commercial, or not-for-profit sector.

Availability of data and materials

All data generated during this study are included in this article and supplementary information files.

Ethics approval and consent to participate

Not applicable.

Consent for publication

Not applicable.

Competing interests

The authors declare that they have no competing interests.

\section{Publisher's Note}

Springer Nature remains neutral with regard to jurisdictional claims in published maps and institutional affiliations.

\section{Author details}

'Department of Clinical Sciences, Carlson College of Veterinary Medicine, Oregon State University, Corvallis, OR 97331, USA. ²Department of Biomedical Sciences, Carlson College of Veterinary Medicine, Oregon State University, Corvallis, OR 97331, USA. 


\section{Received: 2 October 2018 Accepted: 11 February 2019} Published online: 18 February 2019

\section{References}

1. Anderson ME. Update on survival in osteosarcoma. Orthop Clin North Am 2016;47(1):283-292. doi: https://doi.org/10.1016/j.ocl.2015.08.022. PubMed PMID: 26614941

2. Marko TA, Diessner BJ, Spector LG. Prevalence of Metastasis at Diagnosis of Osteosarcoma: An International Comparison. Pediatr Blood Cancer. 2016; 63(6):1006-1011. doi: https://doi.org/10.1002/pbc.25963. PubMed PMID: 26929018; PMCID: PMC4833631.

3. Mueller F, Fuchs B, Kaser-Hotz B. Comparative biology of human and canine osteosarcoma. Anticancer Res. 2007:27(1A):155-64.

4. Barroga E, Kadosawa T, Okumura M. Establishment and characterization of the growth and pulmonary metastasis of a highly lung metastasizing cell line from canine osteosarcoma in nude mice. J Vet Med Sci 1999;61:361-7. PubMed PMID: doi:https://doi.org/10.1292/jvms.61.361.

5. Collet C, Schiltz C, Geoffroy V. The serotonin 5-HT2B receptor controls bone mass via osteoblast recruitment and proliferation. FASEB J. 2008;22:418-27.

6. Klein-Nulend J, Westbroek I, van der Plas A. Expression of serotonin receptors in bone. J Bone Miner Res 2001;16:S176 - S.

7. Westbroek I, van der Plas A, de Rooij K. Expression of serotonin receptors in bone. J Biol Chem 2001;276:28961-8. PubMed PMID: doi:https://doi.org/10. 1074/jbc.M101824200.

8. Bracha S, Viall A, Goodall C, Stang B, Ruaux C, Seguin B, Chappell PE. The expression and role of serotonin receptor 5HTR2A in canine osteoblasts and an osteosarcoma cell line. BMC Vet Res. 2013;9:251. doi: https://doi.org/10. 1186/1746-6148-9-251. PubMed PMID: 24330646; PMCID: PMC3895671.

9. Hu CD, Choo R, Huang J. Neuroendocrine differentiation in prostate cancer: a mechanism of radioresistance and treatment failure. Front Oncol. 2015; 5(90). https://doi.org/10.3389/fonc.2015.00090. PubMed PMID: 25927031 PMC4396194.

10. Quiros-Gonzalez I, Sainz RM, Hevia D, Mayo JC. MnSOD drives neuroendocrine differentiation, androgen independence, and cell survival in prostate cancer cells. Free Radic Biol Med 2011;50(4):525-536. doi: https:// doi.org/10.1016/j.freeradbiomed.2010.10.715. PubMed PMID: 21056653.

11. Walker GE, Antoniono RJ, Ross HJ, Paisley TE, Oh Y. Neuroendocrine-like differentiation of non-small cell lung carcinoma cells: regulation by CAMP and the interaction of mac25/IGFBP-rP1 and 25.1. Oncogene 2006;25(13): 1943-1954. doi: https://doi.org/10.1038/sj.onc.1209213. PubMed PMID: 16302002.

12. von Alten J, Fister S, Schulz H, Viereck V, Frosch KH, Emons G, Grundker C. $\mathrm{GnRH}$ analogs reduce invasiveness of human breast cancer cells. Breast Cancer Res Treat 2006;100(1):13-21. Epub 2006/06/08. doi: https://doi.org/ 10.1007/s10549-006-9222-z. PubMed PMID: 16758121.

13. Harrison GS, Wierman ME, Nett TM, Glode LM. Gonadotropin-releasing hormone and its receptor in normal and malignant cells. Endocr Relat Cancer 2004;11(4):725-748. doi: https://doi.org/10.1677/erc.1.00777. PubMed PMID: 15613448.

14. Kakar SS, Jennes L. Expression of gonadotropin-releasing hormone and gonadotropin-releasing hormone receptor mRNAs in various nonreproductive human tissues. Cancer Lett 1995;98(1):57-62. PubMed PMID: 8529206.

15. Bhattacharya M, Babwah AV. Kisspeptin: beyond the brain. Endocrinology 2015;156(4):1218-1227. Epub 2015/01/16. doi: https://doi.org/10.1210/en. 2014-1915. PubMed PMID: 25590245.

16. Wang FS, Chen H, Wu ZY, Lin JH. KISS1 expression in osteosarcoma: high in chinese clinical cases, but lower in cell lines. Asian Pac J Cancer Prev 2011; 12(12):3229-3234. Epub 2011/01/01. PubMed PMID: 22471458.

17. Zhang Y, Tang YJ, Li ZH, Pan F, Huang K, Xu GH. KiSS1 inhibits growth and invasion of osteosarcoma cells through inhibition of the MAPK pathway. Eur J Histochem. 2013;57(4):e30. Epub 2014/01/21. doi: https://doi.org/10.4081/ ejh.2013.e30ejh.2013.e30 [pii]. PubMed PMID: 24441183; PMCID: 3896032.

18. Horwood NJ, Elliott J, Martin TJ, Gillespie MT. Osteotropic agents regulate the expression of osteoclast differentiation factor and Osteoprotegerin in osteoblastic stromal cells. Endocrinology. 1998;139(11):4743-6. https://doi. org/10.1210/endo.139.11.6433.

19. Dougall WC, Chaisson M. The RANK/RANKL/OPG triad in cancer-induced bone diseases. Cancer Metastasis Rev. 2006:25(4):541-9. https://doi.org/10. 1007/s10555-006-9021-3.
20. Bord S, Ireland DC, Beavan SR, Compston JE. The effects of estrogen on osteoprotegerin, RANKL, and estrogen receptor expression in human osteoblasts. Bone. 2003;32(2):136-41. https://doi.org/10.1016/S87563282(02)00953-5.

21. Good CR, O'Keefe RJ, Puzas JE, Schwarz EM, Rosier RN. Immunohistochemical study of receptor activator of nuclear factor kappa-B ligand (RANK-L) in human osteolytic bone tumors. J Surg Oncol. 2002;79(3): 174-9. https://doi.org/10.1002/jso.10067.

22. Dolcet X, Llobet D, Pallares J, Matias-Guiu X. NF-kB in development and progression of human cancer. Virchows Arch. 2005;446(5):475-82. https:// doi.org/10.1007/s00428-005-1264-9.

23. Schubert A, Schulz H, Emons G, Gründker C. Expression of osteoprotegerin and receptor activator of nuclear factor-KB ligand (RANKL) in HCC70 breast cancer cells and effects of treatment with gonadotropin-releasing hormone on RANKL expression. Gynecol Endocrinol. 2008;24(6):331-8. https://doi.org/ 10.1080/09513590802095845

24. Zhang G, Li J, Purkayastha S, Tang Y, Zhang H, Yin Y, Li B, Liu G, Cai D. Hypothalamic programming of systemic ageing involving IKK- $\beta$ NF-KB and GnRH, Nature 2013;497:211. doi: https://doi.org/10.1038/nature12143, https://www.nature.com/articles/nature12143\#supplementary-information.

25. Golden D, Saria EA, Hansen MF. Regulation of osteoblast migration involving receptor activator of nuclear factor-kappa B (RANK) signaling. J Cell Physiol 2015;230(12):2951-2960. doi: https://doi.org/10.1002/jcp.25024. PubMed PMID: 25893522.

26. Albers-Wolthers KH, de Gier J, Kooistra HS, Rutten VP, van Kooten PJ, de Graaf JJ, Leegwater PA, Millar RP, Schaefers-Okkens AC. Identification of a novel kisspeptin with high gonadotrophin stimulatory activity in the dog. Neuroendocrinology 2014;99(3-4):178-189. Epub 2014/06/07. doi: https:// doi.org/10.1159/000364877000364877 [pii]. PubMed PMID: 24902774.

27. Chappell PE, White RS, Mellon PL. Circadian gene expression regulates pulsatile gonadotropin-releasing hormone $(\mathrm{GnRH})$ secretory patterns in the hypothalamic GnRH-secreting GT1-7 cell line. J Neurosci. 2003;23(35): 11202-11213. Epub 2003/12/06. doi: 23/35/11202 [pii]. PubMed PMID: 14657179; PMCID: 2932475.

28. Krsmanovic LZ, Martinez-Fuentes AJ, Arora KK, Mores N, Navarro CE, Chen HC, Stojilkovic SS, Catt KJ. Autocrine regulation of gonadotropin-releasing hormone secretion in cultured hypothalamic neurons. Endocrinology 1999; 140(3):1423-1431. Epub 1999/03/06. PubMed PMID: 10067871.

29. Chen SQ, Chen ZH, Lin SY, Dai QB, Fu LX, Chen RQ. KISS1 methylation and expression as predictors of disease progression in colorectal cancer patients. World J Gastroenterol. 2014;20(29):10071-10081. doi: https://doi.org/10. 3748/wjg.v20.i29.10071. PubMed PMID: 25110434; PMCID: PMC4123336.

30. Jarzabek K, Koda M, Kozlowski L, Milewski R, Wolczynski S. Immunohistochemical study of KiSS1 and KiSS1R expression in human primary breast cancer: Association with breast cancer receptor status, proliferation markers and clinicopathological features. Histol Histopathol. 2015;30(6):715-723. doi: https://doi.org/10.14670/HH-30.715. PubMed PMID: 25535062

31. Kostakis ID, Agrogiannis G, Vaiopoulos AG, Mylona E, Patsouris E, Kouraklis G, Koutsilieris M. A clinicopathological analysis of KISS1 and KISS1R expression in colorectal cancer. APMIS 2015;123(7):629-637. doi: https://doi.org/10. 1111/apm.12397. PubMed PMID: 26010933.

32. Teplyuk NM, Galindo M, Teplyuk VI, Pratap J, Young DW, Lapointe D, Javed A, Stein JL, Lian JB, Stein GS, van Wijnen AJ. Runx2 regulates G proteincoupled signaling pathways to control growth of osteoblast progenitors. J Biol Chem. 2008;283(41):27585-97. https://doi.org/10.1074/jbc.M802453200.

33. Dotterweich J, Tower RJ, Brandl A, Müller M, Hofbauer LC, Beilhack A, Ebert R, Glüer CC, Tiwari S, Schütze N, Jakob F. The KISS1 receptor as an in vivo microenvironment imaging biomarker of multiple myeloma bone disease. PLoS One. 2016;11(5):e0155087. https://doi.org/10.1371/journal.pone. 0155087.

34. Schmidt E, Haase M, Ziegler E, Emons G, Grundker C. Kisspeptin-10 inhibits stromal-derived factor 1-induced invasion of human endometrial cancer cells. Int J Gynecol Cancer 2014;24(2):210-217. doi: https://doi.org/10.1097/ IGC.0000000000000050. PubMed PMID: 24407584.

35. Tan K, Cho SG, Luo W, Yi T, Wu X, Siwko S, Liu M, Yuan W. KiSS1-induced GPR54 signaling inhibits breast cancer cell migration and epithelialmesenchymal transition via protein kinase D1. Curr Mol Med 2014;14(5): 652-662. PubMed PMID: 24894166.

36. Usui S, Iso Y, Sasai M, Mizukami T, Mori H, Watanabe T, Shioda S, Suzuki H. Kisspeptin-10 induces endothelial cellular senescence and impaired 
endothelial cell growth. Clin Sci (Lond) 2014;127(1):47-55. doi: https://doi. org/10.1042/CS20130505. PubMed PMID: 24405415.

37. Cho SG, Wang Y, Rodriguez M, Tan K, Zhang W, Luo J, Li D, Liu M. Haploinsufficiency in the prometastasis Kiss1 receptor Gpr54 delays breast tumor initiation, progression, and lung metastasis. Cancer Res. 2011;71(20): 6535-6546. doi: https://doi.org/10.1158/0008-5472.CAN-11-0329. PubMed PMID: 21852382; PMCID: PMC4949591.

38. Cvetkovic D, Dragan M, Leith SJ, Mir ZM, Leong HS, Pampillo M, Lewis JD, Babwah AV, Bhattacharya M. KISS1R induces invasiveness of estrogen receptor-negative human mammary epithelial and breast cancer cells. Endocrinology 2013;154(6):1999-2014. Epub 2013/03/26. doi: https://doi.org/ 10.1210/en.2012-2164en.2012-2164 [pii]. PubMed PMID: 23525242

39. Zajac M, Law J, Cvetkovic DD, Pampillo M, McColl L, Pape C, Di Guglielmo GM, Postovit LM, Babwah AV, Bhattacharya M. GPR54 (KISS1R) transactivates EGFR to promote breast cancer cell invasiveness. PLoS One. 2011:6(6): e21599. doi: https://doi.org/10.1371/journal.pone.0021599. PubMed PMID: 21738726; PMCID: PMC3125256.

40. Schubert A, Schulz H, Emons G, Grundker C. Expression of osteoprotegerin and receptor activator of nuclear factor-kappaB ligand (RANKL) in HCC70 breast cancer cells and effects of treatment with gonadotropin-releasing hormone on RANKL expression. Gynecol Endocrinol 2008;24(6):331-338. doi: https://doi.org/10.1080/09513590802095845. PubMed PMID: 18584413.

41. Hanahan D, Weinberg RA. The hallmarks of cancer. Cell 2000;100(1):57-70. PubMed PMID: 10647931

42. Hanahan D, Weinberg RA. Hallmarks of cancer: the next generation. Cell 2011;144(5):646-674. doi: https://doi.org/10.1016/j.cell.2011.02.013. PubMed PMID: 21376230

Ready to submit your research? Choose BMC and benefit from:

- fast, convenient online submission

- thorough peer review by experienced researchers in your field

- rapid publication on acceptance

- support for research data, including large and complex data types

- gold Open Access which fosters wider collaboration and increased citations

- maximum visibility for your research: over $100 \mathrm{M}$ website views per year

At $\mathrm{BMC}$, research is always in progress.

Learn more biomedcentral.com/submissions 